\title{
Control of Crop Harvesting and Transport Process by Kanban Mechanism
}

\author{
Yu Lin $\mathrm{Li}^{1,2}$, Shu Ping $\mathrm{Yi}^{1,{ }^{1}}$, Hai Cao Song ${ }^{2}$ and $\mathrm{Na} \mathrm{Liu}{ }^{2}$ \\ ${ }^{1}$ College of Mechanical Engineering, Chongqing University, Chongqing, 400030, China \\ ${ }^{2}$ College of Mechanical and Electrical Engineering, Shihezi University, Shihezi, 832000, China
}

\begin{abstract}
Crop harvesting processes involve a number of interconnected logistical actives between different functional units. Delays are often experienced due to bad cooperation between heterogeneous cooperating machines. In order to increase the degree of coordination between harvesters and tractors, and eliminate non-value-adding wastes from such logistics processes, in this paper, a theoretical approach to the representation of how to build an agricultural field logistics control system with Kanban technique for crop harvesting operations has been presented. By aggregating crop harvesting and transport process into different stages, a single-stage Kanban control system for crop harvesting operations can be built under the JIT philosophy. It has been shown that the Kanban technique can be introduced to improve this type of transport logistics process. This will provide insights for the enhanced management of field logistics systems.
\end{abstract}

Keywords: Agricultural field operations, process improvement, Kanban control, Queuing Theory.

\section{INTRODUCTION}

Crop harvesting operations are executed by heterogeneous cooperating machines, such as harvesters, transport units and preprocessing equipment. The coordination of logistical activities between different functional units, in most realworld cases, is performed based on the experience of the operators. "Delays are often experienced due to bad cooperation between harvesters and transport vehicles, increasing the overall duration of the harvest process" [1]. Consequently, an effective field logistic control mechanism is most essential to keep the harvester operating constantly at minimum cost and higher efficiency.

Numerous previous approaches in the literature have been used to model and analyze different aspects of the crop harvesting and transport system, which involve simulation [2-4], mathematical programming techniques [5-7] and a combination of modeling and solution techniques [7]. These approaches were applied to commodities such as sugarcane, energy crops, cotton, grains, forage, wood products [8], orange [9], and wine grape [10], etc. The aim was to minimize total cost and increase efficiency through the optimization of fleet sizing and task scheduling. Recently, comprehensive researches in the field logistics level have been conducted on the opportunities and methodologies from the industrial domain. Bochtis and Sørensen [11] developed a methodology for casting the scheduling and planning problems of transport units as VRPTW examples. Sørensen and Bochtis [12] developed a conceptual model based on a participatory approach for the agricultural fleet management. Jensen et al. [13] developed a path planning method involving the genera

*Address correspondence to this author at the College of Mechanical Engineering, Chongqing University, Chongqing, 400030, China;

Tel: +86-023-65106939; E-mail: yshuping@cqu.edu.cn tion of optimal in-field and inter-field paths to be followed by a transport unit cooperating with a primary unit.

Although many researchers have developed a number of methods to improve the performance of harvesting operations, there is still considerable work that can be done in this field to develop new tools to achieve leanness [5]. Higgins et al. [14] highlighted that JIT thinking and tools can be a promising way of improving the agricultural chains. Typically, a simple but efficient control policy for agricultural field operations (AFO) as seen in the industrial domain is the Kanban system, which was first introduced by Taichi Ohno, the manager of Toyota Motors is used to coordinate the material and information flow between the different stages [15]. The success of Toyota and other Japanese enterprises during the 1970s has attracted the attendance of researchers and practitioners [16]. Since then, numerous variations of the Kanban system were created to fulfill specific needs of a production system. Practices show that Kanban system is easy to understand, highly visible, reliable, interlinks the operations tightly, emphasizes operations and quality improvement and is cheap to implement [17].

Hence, the primary objective of this paper is to present a conceptual application of the Kanban-type pull control mechanism within the domain of agricultural field logistics. It aims at increasing the degree of coordination between harvesters and tractors, and eliminating non-value-adding wastes from the crop harvesting and transport process. In the next section, a single-stage Kanban system was built for crop harvesting and transport operations, and then the control issue of the material and information flow between harvesters and tractors was addressed by Kanban technique. Finally, an instance of cotton harvesting and transport operations is designed to demonstrate the effectiveness of the Kanban approach. 


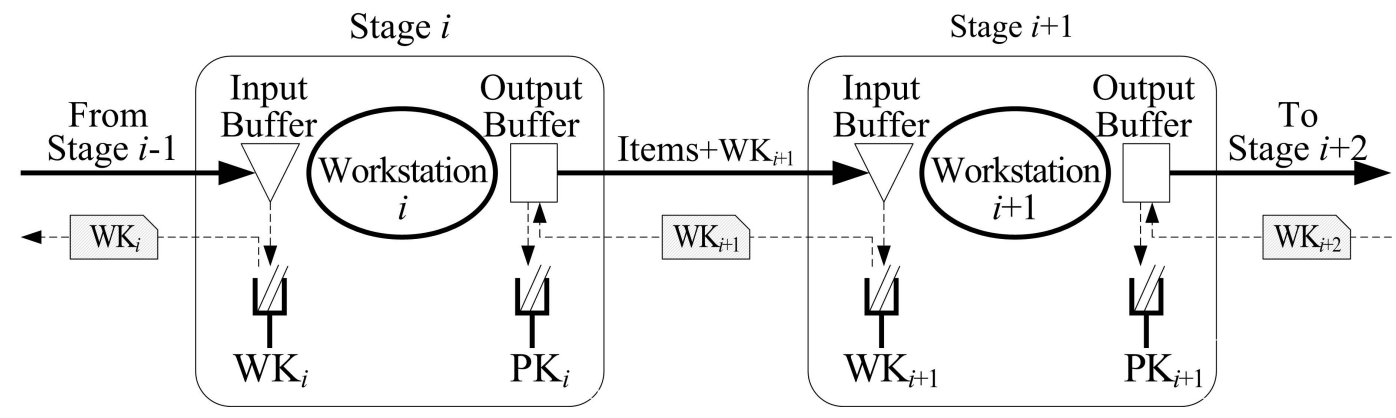

Fig. (1). Kanban control system with several stages.

\section{PRELIMINARIES AND METHODS}

\subsection{The Traditional Kanban System}

Kanban is a technique for maintaining an orderly flow of material and closely associated with the just-in-time philosophy $[18,19]$. To implement a Kanban-type control policy, a common approach is to aggregate process operations into several stages. As shown in Fig. (1), each stage consists of a workstation which is comprised of a set of one or more machines, an input buffer and an output buffer. The workstation contains items that are "either waiting for or receiving service at the different machines, referred to as the work-inprocess (WIP) of the stage. The output buffer contains the finished items of the stage, referred to as the finished goods inventory (FGI) of the stage."[20] Coordination between any pair of related stages $i$ and $i+1$ works as follows [21]:

(1) The container along with the withdrawal Kanban (WK) is moved from the succeeding workstation $i+1$ to the preceding workstation $i$ and placed in the output buffer of workstation $i$.

(2) The finished items of workstation $i$ are subsequently loaded into the container, while the production Kanban (PK) attached to those items is removed and placed in the PK box (or post) of the workstation $i$. The workstation $i$ is then authorized by the PK to start working on a new item.

(3) The container along with the items and WK are moved again to the succeeding workstation $i+1$. Then the items are delivered to the input buffer of the workstation $i+1$, while the WK is detached from the container and placed in the WK box (or post) of workstation $i+1$.

(4) When the on-hand inventory in the input buffer of the workstation $i+1$ reaches the reorder point, then the steps from 1 to 3 are repeated.

The Kanban system (KS) described above has proven to be successful in deterministic production environments with a smooth and stable demand and lead time. Whereas in many practical situations, production systems are fraught with numerous types of uncertainties such as demand variations, breakdowns and other types of planned or unplanned interruptions [22]. In order to minimize the variation caused by a variety of factors, more than thirty variations of the Kanban system summarized by Junior and Filho [23] were developed as alternatives to the material and information flow control in stochastic and unstable demand environments. These variations have promoted the applications of Kanban systems to a large variety of industries.

\subsection{Field Logistics and Crop Harvesting Scenarios}

Agricultural field operations (AFOs) can be categorized in three general types: material input operations (e.g., fertilization, seeding, spraying etc.), material output operations (e.g., harvesting) and neutral operations (e.g., tillage, cultivation, seedbed preparation, windrowing, hay baling, hay conditioning etc.) [24]. All these operations are mainly executed by primary units (PUs) (e.g., harvesters, cultivators, application units etc.). Due to the capacity limit of PUs during these operations, the timely replenishment of necessary items, such as fertilizer, pesticide, seeds, fuel, and empty hoppers, are performed with the help of the service units (SUs) (e.g., refilling units, refueling units, transport carts etc.), keeping the PUs operating constantly. Consequently, the different functional units located in different places compose an agricultural field logistics system.

In regard to the crop harvesting operations, there are two main scenarios, i.e., continuous and intermittent harvesting under which harvesters and transport vehicles need to operate and coordinate [1]. This work mainly considered a continuous harvesting under a given field work pattern, headland pattern, which includes (a) adjacent and (b) nonadjacent traversal for covering a crop field as shown in Fig. (2). The traversal sequence of field tracks and vehicle routing (including harvesting and transporter) is planned in advance. During such operations, crop harvesting is carried out by one or more harvesters that pull the biomass from the plant in the field. The biomass is collected in a hopper on the harvester. When the harvester reaches its specified hopper capacity or load threshold, a transport vehicle approaches the harvester to unload material meanwhile the harvester stops in the field. After finishing the material transfer, the transport vehicle carries this material to a facility unit (e.g., reprocessing unit, factory, silo or farm depot, etc.), while the harvester continues harvesting.

\subsection{Kanban system in harvesting operations}

A logistical improvement during harvesting operations involves more rational material flows between different functional units in the chain. According to the implementation of Kanban principle, the logistics process of crop harvesting and transport can be decomposed into two workstations related each other, i.e., facility units (FUs) and primary units (PUs). The former consists of one or more same or different functional units which can be silos, farm depots, preprocessing equipment, or factories. The function of which can be defined as the "production" of empty containers for PUs. The latter involves one or more identical or non- 

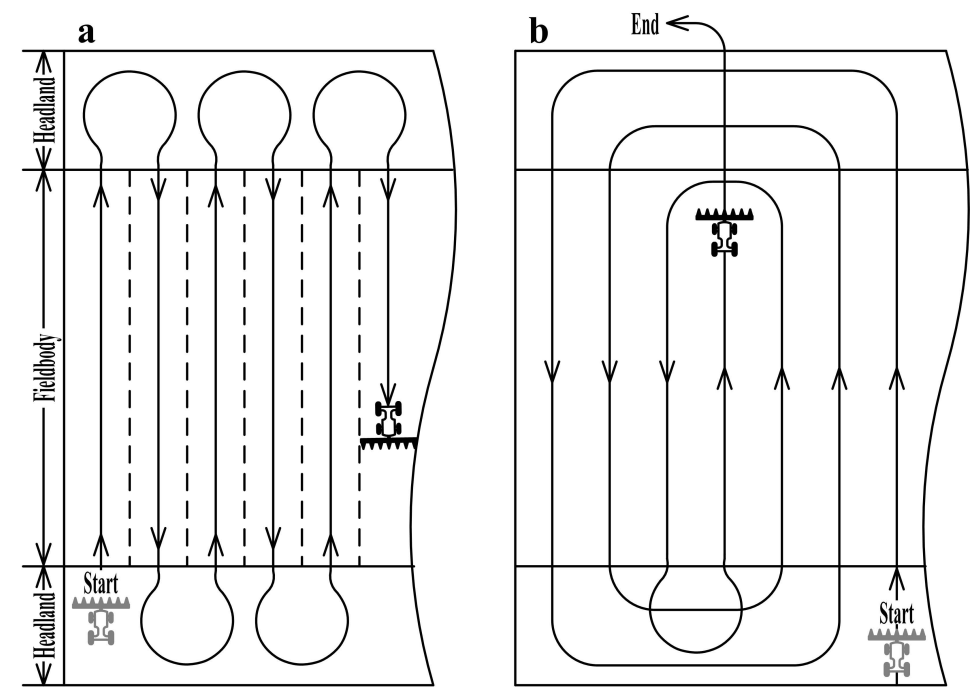

Fig. (2). Headland pattern: (a) adjacent and (b) nonadjacent traversal.

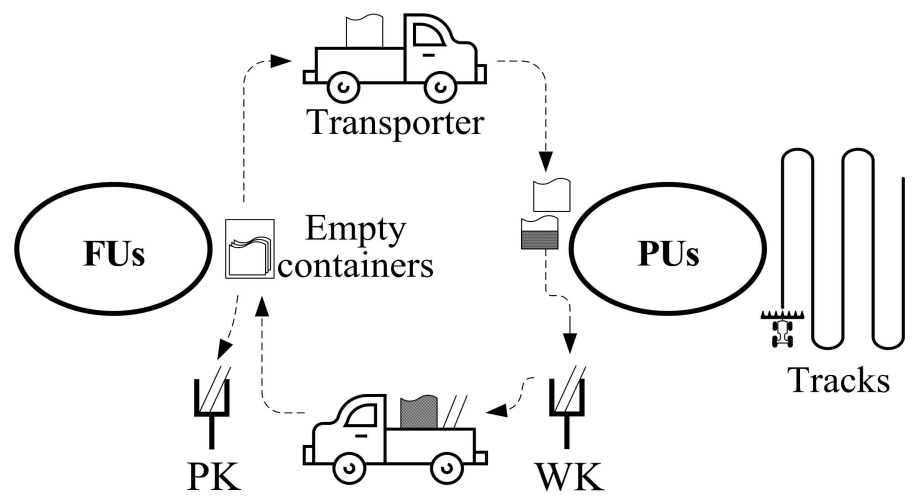

Fig. (3). A single-stage Kanban system in OMF operations.

identical harvesters. In this sense, both the FUs and the PUs constitute the preceding and successive workstations of such a field logistics system, respectively. The material and information flows between FUs and PUs form a Kanban stage. The Kanban corresponds to a card attached to a container on the transporter. Fig. (3) illustrates the Kanban-controlled output material flow (OMF) operation system.

In this system, production is first triggered by the demand at PUs. In a Kanban operation, when the material or capacity of the hopper on the harvester reaches the load threshold, a withdrawal Kanban (WK) attached to the hopper (i.e., container in other word) on the harvester is first detached from the hopper and placed in the WK post. And then the WKs in the post are picked up at a fixed or non-fixed interval and brought to the PK post at the preceding station FUs by transporter. This corresponds to sending a signal to preceding station FUs. The WK displays the preceding and succeeding workstations involved with the items (i.e., empty containers), the quantity of items, the collection interval, etc. The WK is then attached to the container in the store of FUs in place of the PK permitting the worker at preceding station to load or unload the material, i.e., the detached PK triggers the work of preceding station FUs. The empty container together with withdrawal Kanban is brought again to succeeding station PUs by the transporter for fulfilling the demands.
This Kanban cycle realizes a smooth, timely, and not waste flow of items between FUs and PUs [25].

\subsection{Optimization of System Parameters}

To deliver items (i.e., empty containers) by Kanban during harvesting operations, the problem arises here involving how to determine the batch size and the number of batches, how many Kanbans (i.e., containers) are to be employed and what should be the transportation schedules of these containers. These problems should be addressed by minimizing the total cost of the field logistics chain.

Consider the scenarios as mentioned above, let $C_{i}\left(\mathrm{~m}^{3}\right.$ or $k g), i=1,2, \ldots, n$ be the capacity of the material hopper on the $i^{t h}$ harvester, and then the batch size may be assumed as

$Q=\max \left\{C_{i} \mid i=1,2, \ldots, n\right\}$

And the number of batches can be simple to calculate by

$N=\sum_{i=1}^{n}\left\lceil\frac{q \cdot s_{i}}{C_{i}}\right\rceil$

where $q\left(\mathrm{~m}^{3} \cdot \mathrm{m}^{-2}\right)$ is the weight of the material that has to be harvested per square meter of the field areas, and $s_{i}\left(m^{2}\right)$ is 


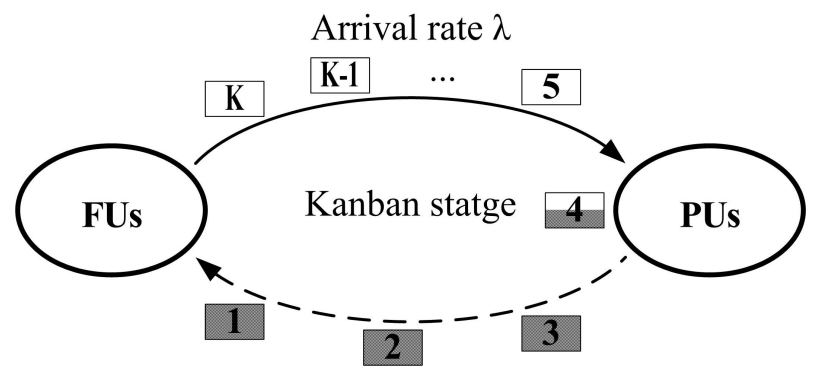

Dispatch rate $\mu$

Fig. (4). Kanban operation in harvesting and transport.

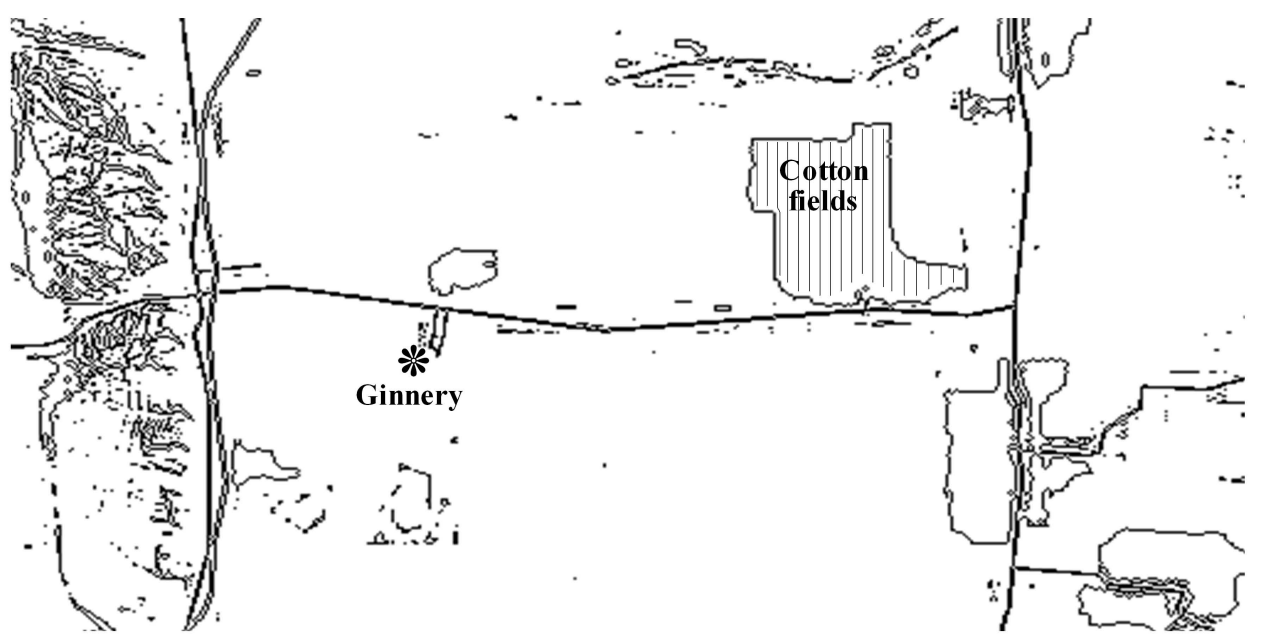

Fig. (5). Location of cotton fields located in Xinjiang, CN.

the coverage areas of the $i^{t h}$ harvester in cycle time $T$ and the symbol denotes the ceiling function.

Next, the optimal number of containers (i.e., Kanbans) needed to ship these batches can be attained by solving the queuing model. Fig. (4) illustrates the Kanban circulation by an $M / M / K$ model. In this model, the customer arrival corresponds to the shipment of a batch, which follows a Poisson process with rate $\lambda$. The server is the empty container, i.e., empty transport vehicle. The service time (includes the transport time, loading and unloading time, etc.) may be exponential with an average service time, $1 / \mu$ in a cycle time $T$.

Consequently, determining the number of Kanbans is equivalent to determining the number of servers (i.e., containers). Higher number of servers improves the service level but, at the same time, increases the setup cost. Thus, a tradeoff between both aspects of service level and setup cost will yield a minimum cost consideration. Then, the expected total cost for the $M / M / K$ model is given as follows.

$z(K)=c_{s} \cdot K+c_{w} \cdot L_{s}$

where

$z(K)$ is the expected total cost of a harvesting-to-transport logistics system (dollars).

$K$ is the number of Kanban containers between FUs and PUs.

$c_{s}$ is the cost per shipment (dollars/shipment). $c_{w}$ is the cost of harvester waiting per unit time in the system (dollars $/ h$ ), if let $v, b$ and $r$ be operating rate, operating width and the cost of harvesting per unit area, respectively, then $c_{w}=v b q r$.

$L_{s}$ is the average number of waiting shipments in the system, $L_{s}=\lambda /(\mu-\lambda)$.

Note that $K$ is a nonnegative integer and $z(K)$ is not continuously differentiable, so the optimal solution can be attained by using the method of marginal analysis, i.e., the inequality conditions $z\left(K^{*}-1\right) \geq z\left(K^{*}\right) \leq z\left(K^{*}+1\right)$ [25].

\section{RESULTS}

An instance of cotton harvesting operations is presented to demonstrate the application of Kanban technique mentioned above. A selected area with areas 9.33 ha located in Xinjiang, China $\left(44^{\circ} 36^{\prime} 55^{\prime \prime} \mathrm{N}, 85^{\circ} 19^{\prime} 86 " \mathrm{E}\right)$. Fig. (5) shows the location of the cotton field and of the ginnery. The example involved three identical harvesters operating in the cotton field. All harvested cottons were transported by transport vehicles to the ginnery (i.e., FUs), about 17 kilometers distance from the field. The transporter speed constants and primary unit (PU) working parameters used are shown in Table 1.

Based on the information mentioned above, the batch size can be $32.5 \mathrm{~m}^{3}$ (about $3856 \mathrm{~kg}$ ) and the number of batches is about 11 shipments. The arrive rate and service rate are 4.72 shipments per hour and 1.06 shipments per hour, 
Table 1. Operational Parameters Used in the Instance

\begin{tabular}{|c|c|}
\hline Operational Parameter & Value \\
\hline \hline Transport vehicle average speed on road, $\mathrm{V}\left(\mathrm{m} \mathrm{s}^{-1}\right)$ & 6.1 \\
\hline Capacity of container on the transporter, $\mathrm{H}\left(\mathrm{m}^{3}\right)$ & 44.0 \\
\hline Capacity of hopper on the harvester, $\mathrm{C}_{\mathrm{i}}\left(\mathrm{m}^{3}\right)$ & 32.5 \\
\hline Harvester average operating rate, $\mathrm{v}\left(\mathrm{m} \mathrm{s}^{-1}\right)$ & 1.6 \\
\hline Harvester operating width, $\mathrm{b}(\mathrm{m})$ & 3.8 \\
\hline Average harvester utilization factor, $\alpha$ & 0.8 \\
\hline
\end{tabular}

Table 2. Results for Different Servers K

\begin{tabular}{|c|c|c|c|}
\hline Number of Servers, $\boldsymbol{K}$ & $\boldsymbol{\lambda} /(\boldsymbol{K} \boldsymbol{\mu})$ & $\boldsymbol{L}_{\boldsymbol{s}}$ & $\boldsymbol{z ( \boldsymbol { K } )}$ \\
\hline \hline 5 & 0.8906 & 10.49 & $\$ 7263$ \\
\hline 6 & 0.7421 & 5.63 & $\$ 3942$ \\
\hline 7 & 0.6361 & 4.82 & $\$ 3400$ \\
\hline 8 & 0.5566 & 4.58 & $\$ 3248$ \\
\hline 9 & 0.4948 & 4.50 & $\$ 3207$ \\
\hline $10^{*}$ & 0.4453 & 4.47 & $\$ 3199$ \\
\hline 11 & 0.4048 & 4.46 & $\$ 3206$ \\
\hline
\end{tabular}

Table 3. Average Results of Some Performance Measures

\begin{tabular}{|c|c|}
\hline Performance Indicator & Average Value \\
\hline \hline The probability that all servers are idle $\left(p_{0}\right)$ & $1.163 \%$ \\
\hline Average time shipment spends in the system $(w)$ & $0.9464 \mathrm{~h}$ \\
\hline Average time shipment spends in the queue $\left(w_{q}\right)$ & $0.0030 \mathrm{~h}$ \\
\hline Average number of shipments in the system $\left(L_{s}\right)$ & 4.4670 \\
\hline Average number of shipments in the queue $\left(L_{q}\right)$ & 0.0142 \\
\hline
\end{tabular}

respectively. According to the queuing theory, the system will have a steady-state solution when $K \mu \geq \lambda$. We have $c_{s}=13.3$ dollars per shipment, $c_{w}=v b q r=686$ dollars per hour, then the results for $K=5,6, \ldots, 11$ can be calculated by equation (3) and shown in Table 2. Table 2 shows that the optimal solution of this Kanban system is $K=10$ for which the expected total cost $z(K)$ is 3199 dollars.

For this $M / M / 10$ system, the results of some performance measures are shown in Table 3. It is observed that the probability that all servers are idle and the average time shipment spends in the queue are both small.

\section{DISCUSSION}

The approach mentioned above was motivated by the facts that both agricultural and industrial logistics control problems are of similar complexity "due to the high number of logistics objects and parameters to be considered", and that the Kanban system is capable of determining when and how much to replenish the PUs with necessary items, particularly, Kanban as a decentralized control approach "al- lows for decreasing the computational effort and coping with dynamics locally" [26].

A major goal of this report has been to theoretically describe how to coordinate the material flow between harvesters and facility units using Kanban technique. An example of cotton harvesting operations was designed to demonstrate the application of Kanban approach to controlling the crop harvesting operations. The results showed that the optimal number of Kanban containers is $K=10$, and the Kanban system seems to be working efficiently with low idle time $\left(p_{0}=1.163 \%\right)$ and a higher service level $\left(w_{q}=0.0030 h\right)$. In the actual case of field operations, eight transport vehicles are assigned to one harvester. This causes the excess of transport vehicle in the farm. The proposed method in this study can reduce the number of transport vehicles and total system cost; on the other hand, Kanban approaches have sufficient capability to coordinate the logistical activities during crop harvesting operations. Further, this approach can be extended to model the input material flow (IMF) operations.

An important point is that the path planning for supporting the SUs was not directly involved in this work, since numerous researches have been carried out on this topic, e.g., references [11, 13] and [27]. These researches constitute the application basis for the proposed single-stage Kanban control system in the OMF operations.

Due to the long distance between different functional units during the harvesting operations, the traditional Kanban cards have a capacity limit in terms of timely transmitting relevant information. Advances in wireless ICTtechnologies, especially the radio frequency identification devices (RFID) can provide "new opportunities to develop more automated and sophisticated electronic Kanban systems" [17]. Therefore, the introduction of emerging information technologies has made it feasible, in principle, to control the field logistics using Kanban technique under just-in-time (JIT) philosophy.

\section{CONCLUSIONS}

In this paper, a theoretical approach to the representation of how to build an agricultural field logistics control system with Kanban technique for crop harvesting operations has been presented. By aggregating crop harvesting and transport process into two different stages, a single-stage Kanban control system for crop harvesting operations can be built under the JIT philosophy. It has been shown that the Kanban technique can be introduced to improve this type of transport logistics process.

The above theoretical approach has provided valuable insights for the improvement of agricultural field logistics process. Further researches can be extended to coordinate the field logistics of IMF operations.

\section{CONFLICT OF INTEREST}

The authors confirm that this article content has no conflicts of interest.

\section{ACKNOWLEDGEMENTS}

The author thanks the editors and the anonymous reviewers for their helpful comments and suggestions. This re- 
search is funded by Research Fund for the Doctoral Program of Higher Education of China (20070611027).

\section{REFERENCES}

[1] O. Ali, B. Verlinden, and D. V. Oudheusden, "Infield logistics planning for crop harvesting operations," Engineering Optimization, vol. 41, no. 2, pp. 183-197, 2009.

[2] E. Arjona, G. Bueno, and L. Salazar, "An activity simulation model for the analysis of the harvesting and transportation systems of a sugarcane plantation," Computers and Electronics in Agriculture, vol. 32 , no. 3 , pp. $247-264,2001$

[3] A. Higgins and I. Davies, "A simulation model for capacity planning in sugarcane transport," Computers and Electronics in Agriculture, vol. 47, no. 2, pp. 85-102, 2005.

[4] R. Jorio, B. Legendre, L. Gautz, and R. Abdellaoui, Eds., "Incorporation of sugarcane harvesting and transport variables into asugarcane harvest and transport scheduling model," in: Proceedings of the 80th Annual Congress of the South African Sugar Technologists' Association, 2006, Durban, South Africa, pp. 71-85.

[5] M. Masoud, E. Kozan, and G. Kent, "A job-shop scheduling approach for optimising sugarcane rail operations," Flexible Services and Manufacturing Journal, vol. 23, no. 2, pp. 181-206, 2011.

[6] B. J. Cochran and R. W. Whitney, Eds., "A technique for designing transport systems for sugarcane," in: Proceedings of the XVI Congress of the International Society of Sugarcane Technologists, 1977, Sao Paulo, Brazil, pp. 2069-2079.

[7] A. J. Higgins and L. A. Laredo, "Improving harvesting and transport planning within a sugar value chain," Journal of the Operational Research Society, vol. 57, no. 4, pp. 367-376, 2006.

[8] P. P. Ravula, R. D. Grisso, and J. S. Cundiff, "Cotton logistics as a model for a biomass transportation system," Biomass and Bioenergy, vol. 32, no. 4, pp. 314-325, 2008.

[9] J. V. Caixeta Filho, "Orange harvesting scheduling management: a case study," Journal of the Operational Research Society, vol. 57, no. 6, pp. 637-642, 2005.

[10] J. C. Ferrer, A. Mac Cawley, S. Maturana, S. Toloza, and J. Vera, "An optimization approach for scheduling wine grape harvest operations," International Journal of Production Economics, vol. 112 , no. 2, pp. 985-999, 2008

[11] D. D. Bochtis and C. G. Sørensen, "The vehicle routing problem in field logistics: Part II," Biosystems Engineering, vol. 105, no. 2, pp. 180-188, 2010.

[12] C. G. Sørensen and D. D. Bochtis, "Conceptual model of fleet management in agriculture," Biosystems Engineering, vol. 105, no. 1, pp. 41-50, 2010.

[13] M. A. F. Jensen, D. Bochtis, C. G. Sørensen, M. R. Blas, and K. L. Lykkegaard, "In-field and inter-field path planning for agricultural transport units," Computers \& Industrial Engineering, vol. 63, no. 4, pp. 1054-1061, 2012.

[14] A. Higgins, P. Thorburn, A. Archer, and E. Jakku, "Opportunities for value chain research in sugar industries," Agricultural Systems, vol. 94, no. 3, pp. 611-621, 2007.

[15] M. D. Al-Tahat, D. Dalalah, and M. A. Barghash, "Dynamic programming model for multi-stage single-product Kanbancontrolled serial production line," Journal of Intelligent Manufacturing, vol. 23, no. 1, pp. 37-48, 2009.

[16] M. L. Spearman, "Customer service in pull production systems," Operations Research, vol. 40, no. 5, pp. 948-958, 1992.

[17] I. A. Kouri, T. J. Salmimaa, and I. H. Vilpola, "The principles and planning process of an electronic kanban system," in Novel algorithms and techniques in telecommunications, automation and industrial electronics, T. Sobh, K. Elleithy, A. Mahmood, and M. A. Karim, Eds. Berlin: Springer Netherlands, 2008, pp. 99-104.

[18] Y. Dallery and G. Liberopoulos, "Extended kanban control system: combining kanban and base stock," IIE Transactions, vol. 32, no. 4, pp. 369-386, 2000.

[19] P. Divakaran and C. T. S. Kumar, "Review of Kanban planning and execution in the context of Lean manufacturing," Information and Knowledge Management, vol. 1, no. 4, pp. 11-18, 2011

[20] Y. Frein, M. D. Mascolo, and Y. Dallery, "On the design of generalized kanban control systems," International Journal of Operations \& Production Management, vol. 15, no. 9, pp. 158-184, 1995.

[21] K. C. Sendil and R. Panneerselvam, "Literature review of JITKANBAN system," The International Journal of Advanced Manufacturing Technology, vol. 32, no. 3-4, pp. 393-408, 2006.

[22] S. M. Gupta, Y. A. Y. Al-Turki, and R. F. Perry, "Flexible kanban system," International Journal of Operations \& Production Management, vol. 19, no. 10, pp. 1065-1093, 1999.

[23] M. L. Junior and M. G. Filho, "Variations of the kanban system: Literature review and classification," International Journal of Production Economics, vol. 125, no. 1, pp. 13-21, 2010.

[24] D. Bochtis, S. Vougioukas, C. Tsatsarelis, and Y. Ampatzidis, "Field operation planning for agricultural vehicles: a hierarchical modeling framework," Agricultural Engineering International: CIGR Journal, vol. 9, pp. 1-11, 2007.

[25] S. Wang and B. R. Sarker, "A single-stage supply chain system controlled by kanban under just-in-Time philosophy," Journal of the Operational Research Society, vol. 55, no. 5, pp. 485-494, 2004.

[26] A. Schuldt, K. A. Hribernik, J. D. Gehrke, K.-D. Thoben, and O. Herzog, Eds., "Cloud computing for autonomous control in logistics," in: Proceedings of the 40th Annual Conference of the German Society for Computer Science (GI 2010), 2010, Leipzig, Germany, pp. 305-310

[27] Y. L. Li and S. P. Yi, "Improving the efficiency of spatially selective operations for agricultural robotics in cropping field," Spanish Journal of Agricultural Research, vol. 11, no. 1, pp. 56-64, 2013.

(C) Li et al.; Licensee Bentham Open.

This is an open access article licensed under the terms of the Creative Commons Attribution Non-Commercial License (http://creativecommons.org/licenses/by-nc/3.0/) which permits unrestricted, non-commercial use, distribution and reproduction in any medium, provided the work is properly cited. 